\title{
MODELO DE COX MULTINIVEL ESTRATIFICADO CON INTERACCIÓN POR ÍNDICE DE RIQUEZA PARA ANÁLISIS DE RIESGO DE MUERTE DE NIÑOS MENORES DE CINCO AÑOS - ENDSA 2008
}

\section{Pamela Córdova Olivera y Marina Yurevna Nikolaeva}

\section{RESUMEN}

Este estudio busca determinar en qué medida el estatus socioeconómico familiar, vinculado a un indicador de riqueza, afecta la probabilidad que los niños menores de cinco años tienen de sobrevivir, utilizando la información de la Encuesta Nacional de Demografía y Salud de Bolivia 2008 (ENDSAB-2008). La población objeto de estudio fueron los niños nacidos vivos, de mujeres entre 15 a 49 años, en los cinco años anteriores a la ENDSAB 2008. La variable dependiente en este estudio es la mortalidad de menores de cinco años (5q0), definida como el riesgo de morir entre el nacimiento y el quinto año de vida. Se estimó un modelo multinivel de Cox estratificado con interacción por las categorías de una variable de estrato denominada como "Índice de Riqueza". Se estimaron 3 modelos multinivel, uno por cada estrato (pobre, medio y rico). El modelo estimado para el estrato pobre del Índice de Riqueza logra explicar una proporción mayor de la varianza entre clústeres, más del $60 \%$, determinado por la zona de residencia, características a nivel niño-madre, hogar y contextual-comunitario. Lo contrario ocurre en el modelo estimado para el estrato rico del Índice de riqueza ya que solo logra explicar el 31\% de la varianza entre clústeres.

Palabras Clave: Mortalidad, Modelo de Cox Estratificado con Interacciones, Modelo Multinivel, Índice de Riqueza.

DOI: 10.23881/idupbo.019.2-7e 